\title{
Polydimethyl siloxane/MIL-101 composites for
}

\section{enhanced toluene adsorption in the presence of}

\section{humidity}

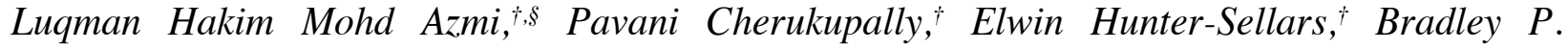
Ladewig, ${ }^{, *}$ Daryl R. Williams. ${ }^{\dagger, *}$

'Department of Chemical Engineering, Imperial College London, South Kensington Campus, Exhibition Road, London, SW7 2AZ, UK.

${ }^{\S}$ Grantham Institute - Climate Change and the Environment, Imperial College London, South Kensington Campus, Exhibition Road, London, SW7 2AZ, UK.

Institute of Micro Process Engineering (IMVT), Karlsruhe Institute of Technology, Hermannvon-Helmholtz-Platz 1, 76344 Eggenstein-Leopoldshafen, Germany.

"Corresponding author’s email: $\underline{\text { d.r.williams@imperial.ac.uk }}$

Keywords: Adsorption, hydrophobic, metal-organic framework (MOF), MIL-101, polydimethylsiloxane (PDMS), toluene, volatile organic compound (VOC). 


\section{ABSTRACT}

Competition between atmospheric moisture and volatile organic compounds (VOCs) for an adsorbent's sites can significantly impact its VOC removal efficiency. The development of moisture-tolerant adsorbents is essential to address this issue. A vapor phase deposition process using polydimethylsiloxane (PDMS) has created a hydrophobic form of the highly porous, normally hydrophilic, MOF MIL-101. After optimizing the PDMS vapor deposition time and molecular weights, hydrophobicity index calculations verified the improved hydrophobicity of the coated MOF (MIL-PDMS-Sigma-0.25) over its pristine form. The surface area, pore volume as well as single component vapor adsorption of water and toluene capacities were also preserved, resulting to similar performance to MIL-101. Toluene-water vapor co-adsorption experiments were conducted at $40 \% \mathrm{RH}$ using two toluene concentrations: $0.5 \% \mathrm{P} / \mathrm{P}_{0}$ and $10 \% \mathrm{P} / \mathrm{P}_{0}$, mimicking environmental VOC and industrial concentrations, respectively. At $0.5 \% \mathrm{P} / \mathrm{P}_{0}$, MIL-PDMSSigma- 0.25 exhibited $60 \%$ higher adsorption capacity and twice the rate of toluene capture relative to pristine MIL-101, as well as a 3-fold higher toluene uptake relative to a commercial activated carbon. Preliminary adsorbent regeneration experiments confirm the stability and performance of MIL-PDMS-Sigma-0.25. Using a simple vapor phase modification, this new MOF-composite material offers superior competitive toluene vapor uptake in humidified real-world conditions at VOC concentrations. 


\section{INTRODUCTION}

The increased awareness of the presence of volatile organic compounds (VOCs) in the urban environment has attracted significant attention in recent years..$^{1-3}$ This concern is amplified as many $\mathrm{VOCs}^{4-7}$ are now being identified as possible causes for many long-term and chronic health conditions.$^{8-11}$ Greater atmospheric dispersion of VOCs also accelerates ozone formation; a leading factor for premature respiratory mortalities. ${ }^{12,13}$ Automobile and industrial emissions are the primary source of outdoor air pollutants, whilst principle indoor VOC sources come from our activities and daily usage of consumer/personal care products. ${ }^{14,15}$ Poor indoor building ventilation, which is compounded by our current interest in minimizing energy losses in buildings, means that private residences and workplace environments can present VOC concentrations which are often significantly higher than the safe limits. ${ }^{11,16,17}$ The importance of air quality is transitioning from being a significant environmental issue to becoming a major global health problem. Therefore, cost-efficient materials that can operate in real world conditions are urgently needed to prevent VOC emission into the environment and to protect public health.

Gas-phase adsorption using porous materials ${ }^{18,19}$ is widely used to remove VOCs from contaminated air. Carbon-based adsorbents are typically used in air cleaning and filtration devices due to their low cost, high porosity, and chemical stability. However, their amorphous and variable chemical structures make targeted removal of specific chemical species challenging. ${ }^{20}$ Recently, metal-organic frameworks (MOFs) emerged as a new class of adsorbents. MOFs are comprised of metal ions bridged by organic linkers with applications covering targeted capture, storage, and release of organic molecules in a controlled fashion. Furthermore, the extensive metal-linker possibilities endow them with orderly pore structure, high surface area, and versatile 
functionalities for VOCs removal. ${ }^{21,22}$ However, one of the greatest challenges in using any solid state adsorbents for capturing environmental VOC contaminants is the omnipresence and competitive presence of environmental moisture.

Water vapor exists at concentrations 10,000 times or higher than many VOC species concentrations (i.e., $1 \%$ compared to $1 \mathrm{ppm}$ ) which results in competitive adsorption processes, favoring water molecules over their VOC companion molecules. An effective adsorbent, especially for removing harmful aromatic hydrocarbons from ambient air, requires a high adsorption affinity for organic molecules whilst rejecting water molecules. ${ }^{20,23,24}$ The uptake capacity and the kinetics of VOC adsorption depend on the type of available surface chemical groups as well as porosity and pore size in the adsorbent. ${ }^{25}$ So, given the known limitations in using conventional carbonous sorbents and the pervasiveness of VOCs in our surrounding, MOFs are potentially the next generation adsorbent material.

MIL-101 is a MOF with high surface area, ready tunability, excellent hydrothermal stability ${ }^{26,27}$ and is frequently studied for VOC capture. ${ }^{28-31}$ Consistent with these characteristics, MIL-101 also showed high water adsorption capacity, implying high hydrophilicity ${ }^{32-38}$ and lack of native hydrophobicity desired for VOC removal in humid environments. Suggested surface modification strategies to increase MOF's hydrophobicity include ligand functionalization with hydrophobic moieties, ${ }^{39,40}$ in-situ hydrophobization ${ }^{41}$ and post-synthetic modification (PSM). ${ }^{42,43}$ PSM is advantageous compared to the other methods which require high cost, involving complex synthesis procedures generating unknown final composite structure, as well as difficulty to scale up for large scale applications. ${ }^{24,42}$ A simple PSM coating technique through vapor deposition of inexpensive 
polymers could be a promising approach to enhance MOF's pollutant selectivity and kinetics of VOCs adsorption from ambient air. ${ }^{21}$

Polydimethylsiloxane (PDMS) is a hydrophobic, silicon-based polymer generally used to manufacture microfluidic structures, industrial sealants, and gaskets. In its non-cross-linked form, this liquid-like polymer has a special permeability feature that permits gas rather than liquid diffusion, hence, rendering it suitable for fabrication of gas separation membranes ${ }^{44}$ It can be used in its pristine form, or as a matrix and co-blended with other additives including MOFs to improve the membranes' performance. ${ }^{45,46}$ This gas phase selectivity, its affordable cost, abundant commercial availability and the hydrophobic nature of PDMS make this polymer an ideal coating to improve MIL-101 hydrophobicity. Previous studies have shown successes performing vaporbased PDMS coating on other porous materials, but very limited data has been reported specifically about their potential industrial performance..$^{47-52}$

In this work, a range of PDMS-coated MIL-101 materials were prepared, and their effectiveness for toluene vapor capture was evaluated. The first phase of this study is dedicated for the optimization of the PDMS vapor coating process, considering specifically PDMS coating time and PDMS molecular weights. In the second phase, the toluene capture performance of the optimized materials will be critically assessed in realistic humidified conditions of $40 \%$ and $25{ }^{\circ} \mathrm{C}$. Water and toluene vapor co-adsorption studies were performed using concentrations likely to be encountered in actual organic vapor capture scenarios; at $0.5 \% \mathrm{P} / \mathrm{P}_{0}$ and $10 \% \mathrm{P} / \mathrm{P}_{0}$, representing broadly environmental VOC and industrial concentrations, respectively. 


\section{MATERIALS AND METHODS}

Materials. All chemicals and reagents were used as received. Chromium (VI) nitrate nonahydrate (98\%), terephthalic acid (99\%), PDMS-Sigma (dynamic viscosity, $\mu=10 \mathrm{cST}$ ), were supplied by Sigma-Aldrich. Glacial acetic acid (100\%) was purchased from VWR and toluene (ACS, 99.5\%) was purchased from Alfa Aesar. Silicone elastomer kit SYLGARD ${ }^{\mathrm{TM}} 184$ was ordered from Dow Chemical Company. This 2-part kit contains PDMS and a curing agent, but only the PDMS was used. Herein denoted as PDMS-Dow $(\mu=3500 \mathrm{cST})$. The reference adsorbent is a commercialized, granular activated charcoal (AC) F400 procured from Chemviron Carbon.

Synthesis of MIL-101. Hydrofluoric acid-free MIL-101 was synthesized by preparing equimolar quantities of chromium (VI) nitrate nonahydrate $(5 \mathrm{mmol}, 2 \mathrm{~g})$, terephthalic acid $(0.83$ g) and acetic acid $(0.29 \mathrm{~mL})$ to be dissolved in $25 \mathrm{~mL}$ of water..$^{53}$ The mixture was later sealed in a Teflon-lined reactor and heated in an oven at $220{ }^{\circ} \mathrm{C}$ for $8 \mathrm{hrs}$. The resultant green crystals were centrifuged and thoroughly rinsed with water $(20 \mathrm{~mL} \times 2)$ and ethanol $(20 \mathrm{~mL} \times 1)$ to remove unreacted terephthalic acid from the product. The suspension was finally dried overnight in a vacuum oven at $120^{\circ} \mathrm{C}$ to obtain the dehydrated MIL-101 product.

PDMS coating method. 50 - $100 \mathrm{mg}$ of activated MIL-101 was spread in a small glass petri dish to form a thin powder layer. The dish containing the substrate was placed inside a larger dish filled with liquid PDMS. Both dishes were covered with aluminium foil and then heated in an oven. The dish containing PDMS-Dow was heated at $235^{\circ} \mathrm{C}$ and PDMS-Sigma at $180{ }^{\circ} \mathrm{C}$ for a series of coating times. After the coating time was completed, the sample was allowed to cool, yielding a range of coated MIL-101 samples designated as MIL-PDMS-XXX-T. The suffix XXX 
describes the PDMS source and T represents the time spent in the oven (hr). Different heating temperatures were used depending on the PDMS boiling points to ensure polymer volatility. ${ }^{54}$ Figure S1 in the Supporting Information shows the gas-phase deposition experimental setup described here.

Material characterization. Powder X-Ray Diffraction (PXRD) spectra were recorded on X'Pert PRO PANalytical diffractometer using $\mathrm{Cu} K \alpha$ radiation $(40 \mathrm{kV}, 20 \mathrm{~mA})$ within a scattering range (20) from $5^{\circ}$ to $30^{\circ}$. The theoretical PXRD spectra of MIL-101 were derived from CCDC code OCUNAC. FTIR spectra were measured with Cary (Agilent, USA) spectrophotometer. Thermal stability of the coated samples was examined using a thermogravimetric analysis (TGA) instrument Netzsch STA 49 F5 Jupiter from 30 to $900{ }^{\circ} \mathrm{C}$ under flowing air $(40 \mathrm{~mL} / \mathrm{min})$ at a heating rate of $20 \mathrm{~K} / \mathrm{min}$. Nitrogen $\left(\mathrm{N}_{2}\right)$ adsorption-desorption measurements were conducted with 3Flex Micromeritics analyzer at $77 \mathrm{~K}$ from partial pressure $\left(\mathrm{P} / \mathrm{P}_{0}\right) 0$ to 0.99 . Prior to testing, the samples were degassed overnight in vacuo at $150^{\circ} \mathrm{C}$. X-ray fluorescence (XRF) measurements for the samples were performed on PANalytical EPSILON 3XLE XRF spectrometer. SEM images were recorded using Zeiss Leo Gemini 1525 operated at $5 \mathrm{kV}$. Brunauer Emmett Teller (BET) method was used to calculate the specific surface area of the adsorbents. Total pore volume and pore size distribution were estimated according to Tarazona NDLFT $\left(\mathrm{N}_{2}\right)$ model by assuming a cylindrical pore geometry. KRÜSS Drop Shape Analyzer was used to measure samples' static water contact angle (WCA) at ambient temperature. 
Single-solvent adsorption measurements. The solvent adsorption experiments were performed at $25{ }^{\circ} \mathrm{C}$ with water and toluene in static mode using IGA-002 (Hiden Isochema, USA) and dynamically using a DVS Resolution (Surface Measurement Systems, UK).

Hydrophobicity Index. An effective VOC adsorbent requires hydrophobicity on both internal pore and external surfaces for optimal organic molecules adsorption. ${ }^{24}$ However, the traditional contact angle method only provides the extent of hydrophobicity for the outer surface, but not for the surface of the internal pores. Furthermore, contact angle measurements do not consider factors specific to adsorption performance including differences in size, volume, and shape of the pores. To address this gap, the internal adsorbent hydrophobicity was evaluated through water adsorption isotherms. An established metric, hydrophobicity index (HI), was used in this study as a comprehensive and quantitative descriptor of pore hydrophobicity. HI takes into account a material's adsorption capacity ratio for a hydrophobic molecule such as toluene ${ }^{55}$ or cyclohexane $^{56}$ relative to water, as obtained from specific single or dual component adsorption experiments. ${ }^{23,57,58}$ Alternatively, some authors have estimated $\mathrm{HI}$ through pore volume measurement from $\mathrm{N}_{2}$ adsorption and volume of desorbed water from TGA analysis ${ }^{59}$ To provide a fair comparison of reported $\mathrm{HI}$ values reported, the mode of the experiment must be specified, either conducted in dynamic (simultaneous exposure of competing species) or static (separate exposure). Equation 1 shows the preferred HI calculation formula used in the current study..$^{23}$

$$
H I_{\text {static }}(x)=\frac{Q_{\text {toluene- } 0.05}}{Q_{\text {water }-x}}
$$

Equation 1 
Where $\mathrm{HI}_{\text {static }}(\mathrm{x})(\mathrm{mol} / \mathrm{mol})$ is the material's molar hydrophobicity index calculated using the quantity of toluene adsorbed at a $5 \% \mathrm{P} / \mathrm{P}_{0}\left(\mathrm{Q}_{\text {toluene-0.05 }}, \mathrm{mol} / \mathrm{g}\right)$ as a function of adsorbed water quantity $\left(\mathrm{Q}_{\text {water- } \mathrm{x}}, \mathrm{mol} / \mathrm{g}\right)$ at different $\mathrm{P} / \mathrm{P}_{0}(\mathrm{x})$.

Competitive adsorption. To mimic real-world conditions, the samples were pre-exposed in separate experiments at 40 and $80 \% \mathrm{P} / \mathrm{P}_{0}$ or $\mathrm{RH}$ of water vapor at $25{ }^{\circ} \mathrm{C}$. It is acknowledged that factors such as geographical, seasonal, and building environments can influence the average building humidity levels, however, $40 \% \mathrm{RH}$ can be reasonably considered as a typical daily average indoor value and is the focus for the current study. At a high humid condition ( $80 \% \mathrm{RH})$, the samples showed negligible toluene uptake because water adsorption process dominated measurable toluene adsorption. The performance of all adsorbents was evaluated at $40 \% \mathrm{RH}$ for two separate toluene concentrations of $0.5 \% \mathrm{P} / \mathrm{P}_{0}(188 \mathrm{ppm})$ and at $10 \% \mathrm{P} / \mathrm{P}_{0}(3750 \mathrm{ppm})$, representing a very high environmental VOC level and concentration from an industrial solvent separation/recovery process, respectively. Even though many actual VOC environmental concentrations would be single digit $\mathrm{ppm},{ }^{60}$ the selected concentrations are still relevant for the VOCs concentrations at indoor and industrial environments.

Moisture stability and adsorbent reusability tests. The materials were assessed for their shortterm stability at a high RH condition when other MOF adsorbents are known to be unstable. Starting with (A) a $40 \% \mathrm{RH}$ background, the samples were first equilibrated with $0.5 \% \mathrm{P} / \mathrm{P}_{0}$ toluene, then exposed to (B) $90 \% \mathrm{RH}$ at $0 \% \mathrm{P} / \mathrm{P}_{0}$ toluene for $24 \mathrm{hrs}$. Finally, they were tested at $40 \% \mathrm{RH}$ and $0.5 \% \mathrm{P} / \mathrm{P}_{0}$ toluene again (C). The toluene uptake before (A) and after (C) the $90 \%$ RH exposure was reported. 
In the reusability experiment, also with $40 \% \mathrm{RH}$ background, to confirm the materials' reusability, the samples were exposed to $10 \% \mathrm{P} / \mathrm{P}_{0}$ toluene for $3 \mathrm{hrs}$ followed by $1 \mathrm{hr}$ of desorption and repeated for 10 experimental cycles. All experiments were conducted at $25^{\circ} \mathrm{C}$.

\section{RESULTS AND DISCUSSION}

Physicochemical properties of the materials. Figure 1A shows the PXRD spectra of the samples. The identical $2 \theta$ peaks at $8.7^{\circ}, 9.3^{\circ}, 10.6^{\circ}$ and $16.9^{\circ}$ exhibited by all coated materials signify their intact crystallinity relative to the theoretical peaks of MIL-101. However, MILPDMS-Dow- 6 exhibited slightly degraded peaks. The high coating temperature of $235^{\circ} \mathrm{C}$ could be the reason for the loss of crystallinity in this sample. The TGA plots in Figure 1B compare the thermal decomposition of PDMS-Sigma samples to the pristine MIL-101 in an air atmosphere. The PDMS coating content in MIL-PDMS-Sigma-0.25 and MIL-PDMS-Sigma-6 was measured as $0.14 \mathrm{wt} \%$ and $0.55 \mathrm{wt} \%$, respectively. Details for the calculation methodology using Equation S1 are given in the Supporting Information. The PDMS coating presence on MIL-101 was identified using FTIR spectroscopy. The FTIR spectra in Figure 1C of all PDMS-coated samples display the characteristic vibration of Si-O-Si bonds. ${ }^{61}$ The chemical stability or leaching of the coating was also studied. Further details can be found in the Supporting Information. The XRF analysis in Fehler! Verweisquelle konnte nicht gefunden werden.D illustrates the cumulative PDMS deposition for different coating times as represented by elemental $\mathrm{Si}$ wt\%. Generally, $\mathrm{Si}$ coating quantities for both PDMS types had plateaued at about $1 \mathrm{hr}$. Figure S2 shows the SEM images for the studied samples. Irrespective of heating temperature, they display the typical octahedral morphology of MIL-101 crystals. 

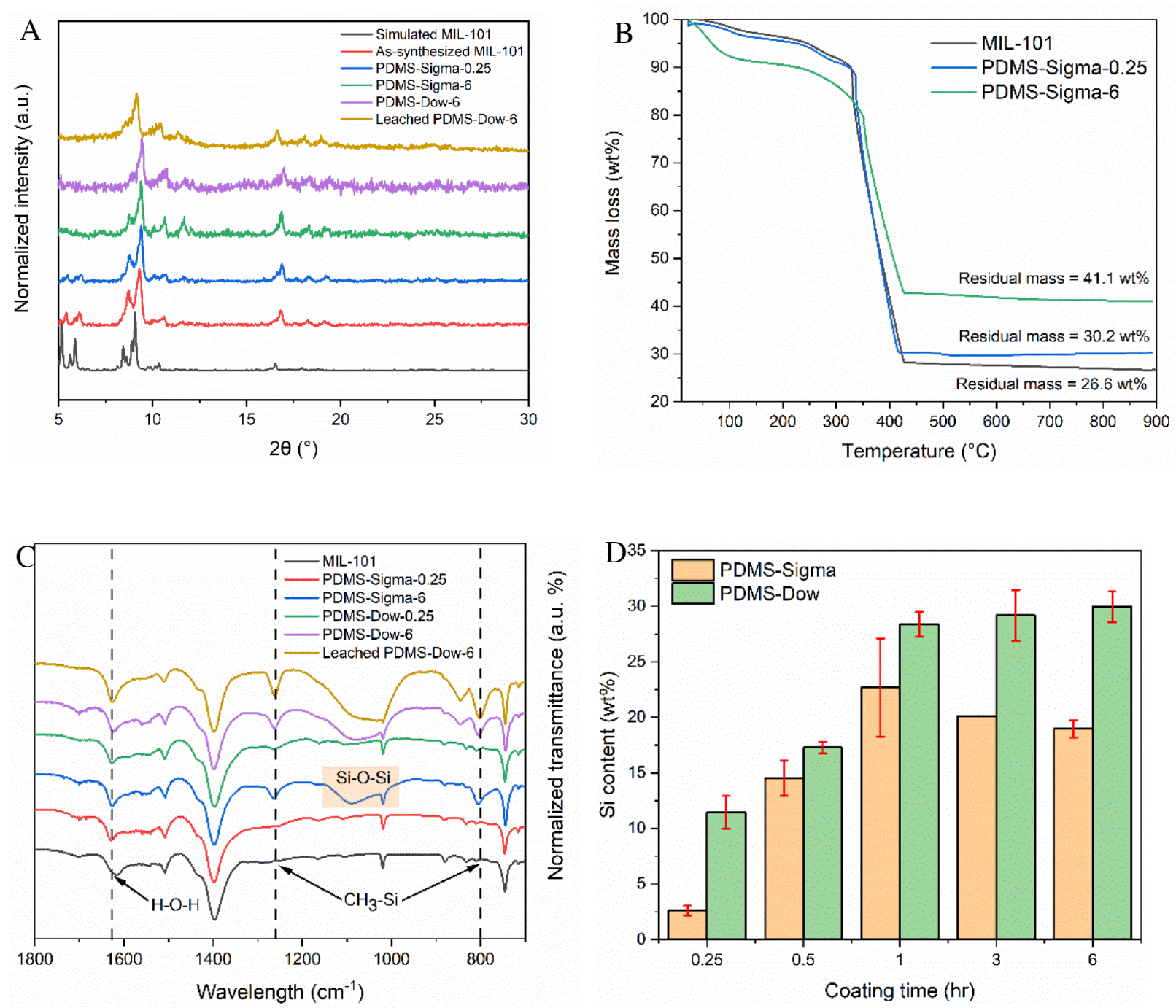

Figure 1. (A) PXRD spectra of PDMS-coated samples. (B) Thermal decomposition profiles of the composites in air atmosphere (40 mL/min). (C) FTIR spectra of the composites. (D) Elemental $\mathrm{Si}$ wt\% quantification by XRF.

BET surface area analysis. In a chemical vapor deposition (CVD), the coating time would directly influence the amount of coating deposited on the outer surface and in the pore surface of the MOFs. Therefore, the effect of PDMS exposure time to the MOF's pore volumes was evaluated 
at 0.25 and 6 hrs. Table 1 provides the details of the BET measurements. The pore size distribution plots can be found in Figure S3 in the Supporting Information. For MIL-PDMS-Sigma, the surface area and the pore volume were $58 \%$ and $55 \%$ higher at $0.25 \mathrm{hr}$ relative to $6 \mathrm{hrs}$. For MIL-PDMSDow, the surface area and the pore volume were $73 \%$ and $67 \%$ higher at $0.25 \mathrm{hr}$ relative to $6 \mathrm{hrs}$. These results suggest that longer exposure times could potentially fill the pores with PDMS.

Notably, when the lower molecular weight PDMS was used (Sigma), and specifically with 0.25 hr coating time, the surface area as well as the pore volume were preserved. MIL-PDMS-Dow0.25 exhibited some pore volume reduction which may be associated with greater pore space occupation by this bulkier and higher molecular weight PDMS. The immediate pore clogging that occurred on MIL-PDMS-Dow-0.25 unlike a gradual Si wt\% rise observed for MIL-PDMS-Sigma0.25 makes the latter PDMS type a better choice to minimize the risks of pore blockage. To further evaluate their adsorption performance corresponding to the available surface area, MIL-PDMS0.25 and MIL-PDMS-6 samples were compared. This study only considered the impact of PDMS molecular weight on adsorbent's pore blockage. A previous report found that fine tuning the polymer chain architecture is also a viable option to achieve excellent PDMS coating without compromising the adsorbent material's porosity. ${ }^{52}$

Table 1. Surface area and water contact angle for all samples before and after 0.25 and $6 \mathrm{hrs}$ of coating time.

\begin{tabular}{|l|l|l|l|}
\hline Sample & $\begin{array}{l}\text { BET surface area } \\
\left(\mathrm{m}^{2} / \mathrm{g}\right)\end{array}$ & $\begin{array}{l}\text { Total pore volume } \\
\left(\mathrm{cm}^{3} / \mathrm{g}\right)\end{array}$ & $\begin{array}{l}\text { Water contact } \\
\text { angle }\left(^{\circ}\right)\end{array}$ \\
\hline MIL-101 & 2710 & 1.035 & 0 \\
\hline
\end{tabular}




\begin{tabular}{|l|l|l|l|}
\hline MIL-PDMS-Sigma-0.25 & 2865 & 1.132 & 0 \\
\hline MIL-PDMS-Sigma-6 & 1192 & 0.475 & $131 \pm 1$ \\
\hline MIL-PDMS-Dow-0.25 & 2398 & 0.936 & 0 \\
\hline MIL-PDMS-Dow-6 & 656 & 0.269 & $133 \pm 3$ \\
\hline Activated carbon (AC) & 1358 & 0.805 & - \\
\hline
\end{tabular}

Water contact angle. The extent of hydrophobicity at the MOF's outer surface and internal pores was evaluated using water contact angles and vapor adsorption-based hydrophobicity index (HI), respectively. The contact angles in Table 1 were measured using sessile drop method with water, though these measurements were not possible for AC due to its granular nature and surface roughness. However, $\mathrm{AC}$ is well known to be a hydrophobic material, being demonstrated by TGA analysis reported elsewhere.$^{53}$ Meanwhile, MIL-101 has a $0^{\circ}$ contact angle with water because of its innate hydrophilicity. After $0.25 \mathrm{hr}$ coating time, for both MIL-PDMS-Sigma and Dow samples, their contact angles are the same with MIL-101 due to low amount of external PDMS coating. After 6 hrs of coating, the deposited PDMS contributed to an increased contact angle $>130^{\circ}$, confirming successful modification from a hydrophilic to a superhydrophobic surface. The influence of time on the sample's hydrophobicity agrees well with other reports in the literature. ${ }^{49,63}$ However, the thickness of the PDMS layers needs precise control to achieve the required degree of wettability change without causing pore blockage.

Water adsorption isotherms. Figure 2A shows the water adsorption and desorption isotherms of all samples. Details on water adsorption mechanisms for MIL-101 have been reported previously, whereby the water molecules initially bind to the metal sites followed by gradual occupation of the mesopores. During this initial stage, additional water build-up leads to formation 
of small hydrogen-bound water clusters. Finally, the water uptake proceeds at a slower rate as the molecules transfer into the large molecular cages and the remaining inter particulate voids before reaching uptake saturation..$^{37,64}$ Water adsorption isotherm for MIL-101 displays a distinct two-step process, firstly from 40 to $45 \% \mathrm{P} / \mathrm{P}_{0}$, and secondly, from 45 to $50 \% \mathrm{P} / \mathrm{P}_{0}$ which confirms the presence of two mesoporous cages with different aperture sizes. ${ }^{38}$

After $0.25 \mathrm{hr}$ coating time, the promising MIL-PDMS-Sigma-0.25 exhibited a $10 \%$ higher uptake in its Type-V water uptake isotherm compared with the pristine form, whilst also exhibiting a $10 \%$ increase in the isotherm inflection point from 45 to $55 \% \mathrm{P} / \mathrm{P}_{0}{ }^{65}$ The inflection in $\mathrm{P} / \mathrm{P}_{0}$ is defined as the point when water adsorption uptake rises steeply due to their complete occupation inside the smaller pore cavity and an indicator of their transfer into the mesoporous cages beyond the $\mathrm{P} / \mathrm{P}_{0}$. The altered surface chemistry on MIL-PDMS-Sigma-0.25 is instrumental in delaying the pore filling processes. The increased $\mathrm{P} / \mathrm{P}_{0}$ arguably hints that the PDMS infiltration into the MOF happens around the mesopore spaces which simultaneously generates an additional water barrier inside the pores.$^{52}$ However, the limited coating quantity may be the reason to only a small shift observed on the onset pore filling pressure for MIL-PDMS-Sigma-0.25. A higher shift is expected if more PDMS coating is incorporated.

For the MIL-101 samples coated at $6 \mathrm{hrs,} \mathrm{their} \mathrm{reductions} \mathrm{in} \mathrm{water} \mathrm{uptake} \mathrm{capacity} \mathrm{correlated}$ with their respective surface area reduction. Despite this CVD technique being commonly used from time to time ${ }^{48,49,51,52}$ the risks of severe pore blockage found in this study indicate the need for a careful application to be an effective means to enhance MIL-101's hydrophobicity. Whilst longer coating times yielded greater surface hydrophobicity, excessive duration produces thicker 
PDMS layers, which negatively impeded pore access. ${ }^{49}$ Both 6 hr-coated MIL-101 exhibited substantial pore blockage; the PDMS-6 version of Dow and Sigma. MIL-PDMS-Dow-6 suffered the highest porosity loss than the other type, hence, the reason to its low water uptake at $80 \% \mathrm{P} / \mathrm{P}_{0}$.

There appears to be a mismatch between a material's surface hydrophobicity and its water adsorption isotherms. The reason is because a WCA measurement can only interrogate the external surface chemistry that highly depends on the surface morphology and structure (i.e., grain size and arrangement). On the other hand, a material's water isotherms are representative of the adsorption chemistry arising from its intrinsic hydrophobicity. The observed WCA is therefore prone to error as a material with high intrinsic hydrophobicity can display a lower WCA than a material of lower intrinsic hydrophobicity if it has more suitable roughness. ${ }^{62,63}$ This behavior is demonstrated by $\mathrm{AC}$ as the intrinsically hydrophobic pores resulted in a slower, gradual water uptake until it is capped by the material surface area. The increasing order of $80 \% \mathrm{P} / \mathrm{P}_{0}$ water uptake quantity can therefore be summarized as follows: MIL-PDMS-Dow- 6 AC $<$ MIL-PDMS-Sigma- 6 <IL$101<$ MIL-PDMS-Sigma-0.25.
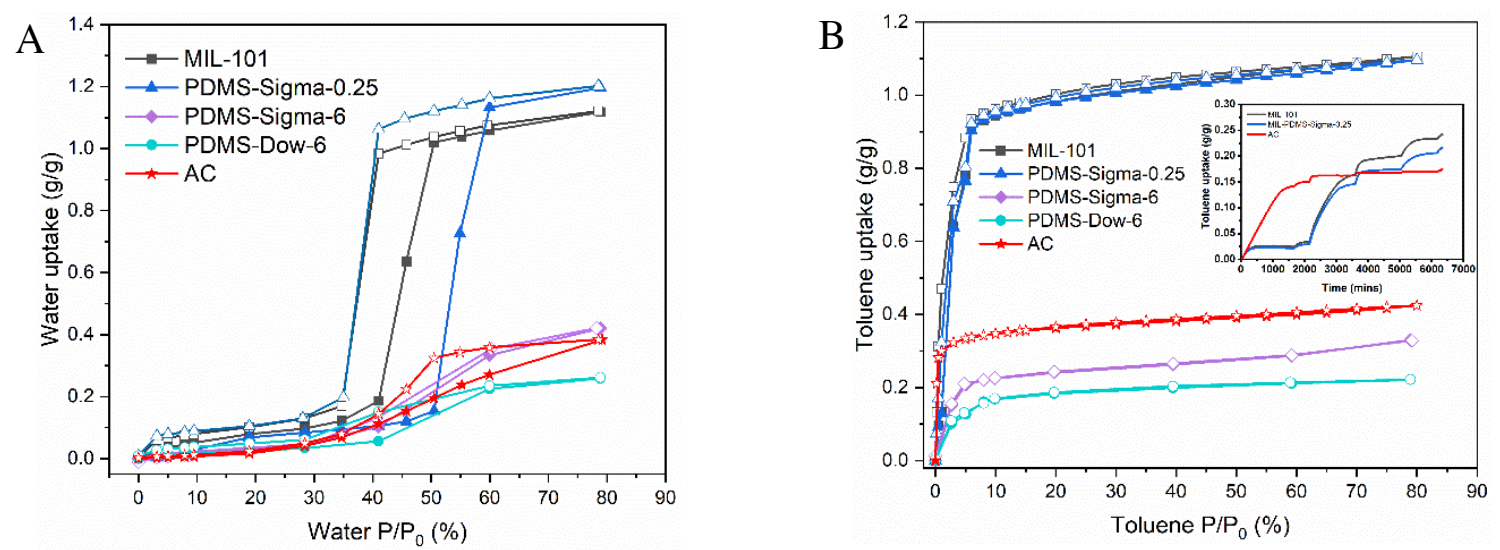
Figure 2. (A) Water and (B) toluene adsorption-desorption isotherms for all studied samples at 25 ${ }^{\circ} \mathrm{C}$. Filled symbols and empty symbols are the adsorption and desorption data points, respectively.

Toluene adsorption isotherms. Figure $2 \mathrm{~B}$ shows the amount of toluene adsorbed by all samples as a function of toluene $\% \mathrm{P} / \mathrm{P}_{0}$. The samples demonstrated rapid toluene adsorption irrespective of PDMS coating amount. At $80 \% \mathrm{P} / \mathrm{P}_{0}$, relative to $\mathrm{MIL}-101$, reductions in the toluene uptake exhibited by the PDMS-coated samples correlate with the materials' surface area reduction. MILPDMS-Sigma-0.25 and MIL-101 have almost identical and the highest adsorption capacity at $80 \%$ $\mathrm{P} / \mathrm{P}_{0}$ of toluene; $110 \mathrm{wt} \%$. This result is also $200 \%$ higher than industrial AC. To examine the adsorption rate at low toluene $\mathrm{P} / \mathrm{P}_{0}$ uptake $\left(<10 \% \mathrm{P} / \mathrm{P}_{0}\right)$, the quantity of toluene uptake was plotted against adsorption time and these are shown in the inset plot. Interestingly, AC showed faster adsorption rate in this condition which reveals the utility of $\mathrm{AC}$ at low $\mathrm{P} / \mathrm{P}_{0}$ when only a single adsorbate is present, whilst MOFs are preferred for adsorbing higher toluene quantities due to their high $80 \% \mathrm{P} / \mathrm{P}_{0}$ adsorption capacities. ${ }^{66}$

Hydrophobicity Index. Figure 3 shows the experimentally estimated HI values as a function of humidity for all samples. Below 10\% RH, the HI value of MIL-PDMS-Sigma-0.25 is between 2 and 8 times higher than MIL-101. Therefore, MIL-PDMS-Sigma-0.25 is expected offer superior VOC capture in low RH environments. Above $10 \% \mathrm{RH}, \mathrm{AC}$ exhibits the highest HI values. This suggests that AC could perform better if the application involves higher humidity between 10 and $50 \%$ RH. Nevertheless, as the humidity level increases, all samples will have been fully saturated with adsorbed water and lose some of their capability to readily adsorb hydrophobic organic molecules present. ${ }^{23}$ 


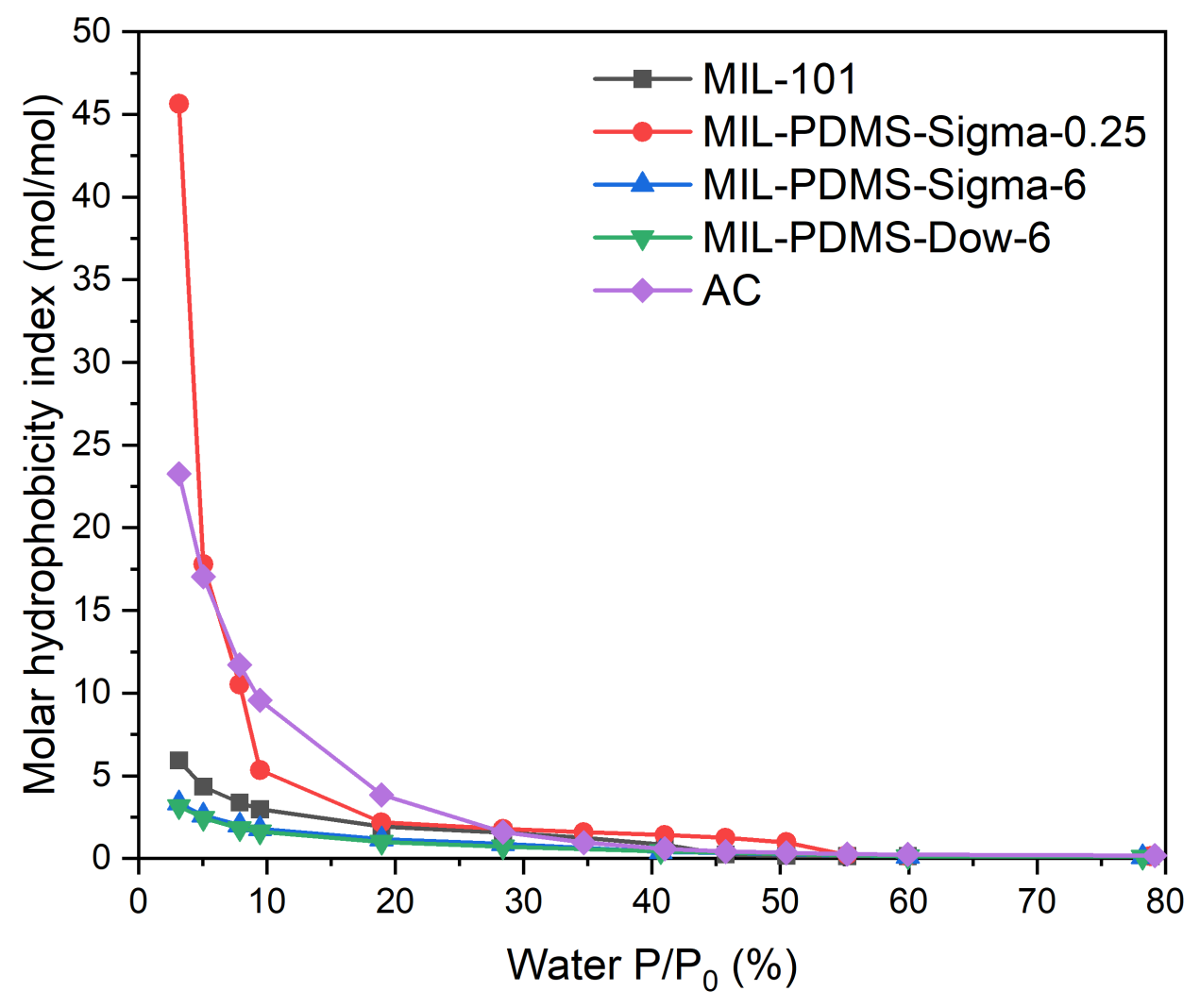

Figure 3. Calculated molar Hydrophobicity Index (HI) for selected samples as a function of water $\mathrm{P} / \mathrm{P}_{\mathrm{o}}$ at $25^{\circ} \mathrm{C}$.

Dual component adsorption isotherms. Figure S4 in the Supporting Information shows the amount of $0.5 \% \mathrm{P} / \mathrm{P}_{0}$ toluene adsorbed by MIL-101 at different water $\mathrm{P} / \mathrm{P}_{0}$ from $0.5 \%, 20 \%, 40 \%$, $60 \%$ to $80 \%$. The amount of toluene co-adsorbed reduced considerably as humidity was increased, especially after $40 \% \mathrm{P} / \mathrm{P}_{0}$. This is the inflection point when MIL-101's pores are occupied with water molecules. Beyond this condition, MIL-101 could not accommodate the incoming toluene molecules due to the material's overly strong water preference as discussed before. ${ }^{30}$ On the 
contrary, the superior toluene uptake displayed in Figure 2B was governed by high isosteric heat of toluene vapor adsorption $\left(\Delta H_{\mathrm{s}, \text { toluene }}=75 \mathrm{~kJ} / \mathrm{mol}\right),{ }^{31}$ suggesting MIL-101's high dry toluene affinity. The next important question will be whether the coating contributes positively to the materials' performance if an average operating condition is applied. Comprehensive material screening was performed, and the adsorption capacities are displayed in Figure 4. From this data, only PDMS-0.25 and PDMS-6 samples were selected for comparison with the pristine MIL-101 and $\mathrm{AC}$.
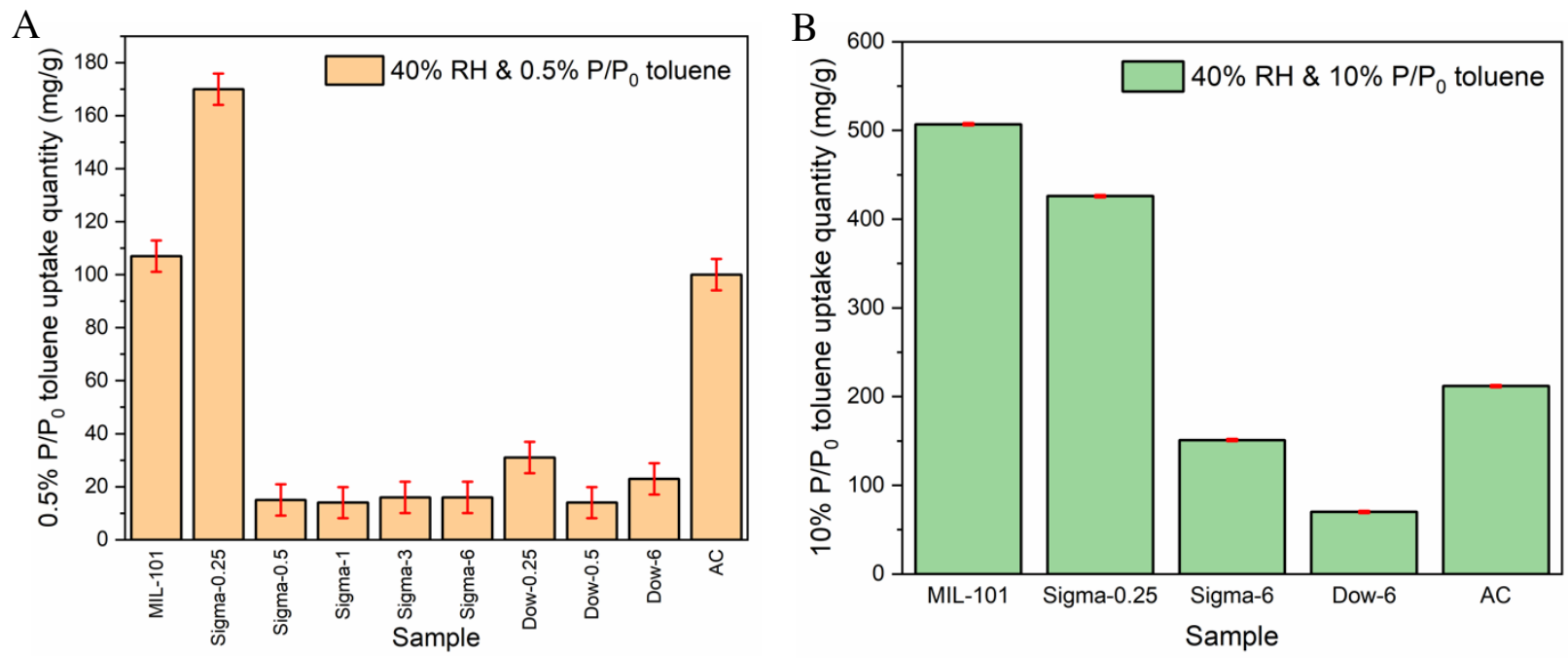

Figure 4. Toluene uptake quantity by PDMS-coated MIL-101 samples at (A) $0.5 \% \mathrm{P} / \mathrm{P}_{0}$ toluene and (B) $10 \% \mathrm{P} / \mathrm{P}_{0}$ toluene. All experiments were performed at $40 \% \mathrm{RH}$ saturation and at $25^{\circ} \mathrm{C}$.

Figure 5A shows the adsorption kinetics by all modified MIL-101 samples at $40 \%$ RH with $0.5 \%$ $\mathrm{P} / \mathrm{P}_{0}$ toluene. For the shorter coating time, MIL-PDMS-Dow- 0.25 toluene uptake is inferior to the improvements shown by MIL-PDMS-Sigma-0.25. For this reason, MIL-PDMS-Dow variants were not taken forward for more detailed studies. The PDMS coating on MIL-PDMS-Sigma-0.25 induced $60 \%$ higher toluene uptake level compared to standard MIL-101, whereas AC severely 
lagged far behind the two MOFs. This outstanding performance of MIL-101 and its PDMS variant is partly because MIL-101 has a large pore volume and pore width which facilitates rapid toluene adsorption. ${ }^{67}$

Figure 5B displays the samples' toluene uptake kinetics at $40 \% \mathrm{RH}$ at $10 \% \mathrm{P} / \mathrm{P}_{0}$ toluene where the pristine MIL-101 outperformed the MIL-PDMS-Sigma- 0.25 uptake by about $19 \%$. The higher toluene affinity shown by MIL-101 despite after being saturated at 40\% RH proves the dominance of inherent hydrogen bonding and $\pi-\pi$ interactions taking place between the ligands and the toluene molecules.$^{68}$ The lower PDMS content that worked at $0.5 \% \mathrm{P} / \mathrm{P}_{0}$ was suppressed at higher toluene level. AC performed poorly again, just like at $0.5 \% \mathrm{P} / \mathrm{P}_{0}$, with slower adsorption kinetics and much lower uptake than the MOFs.
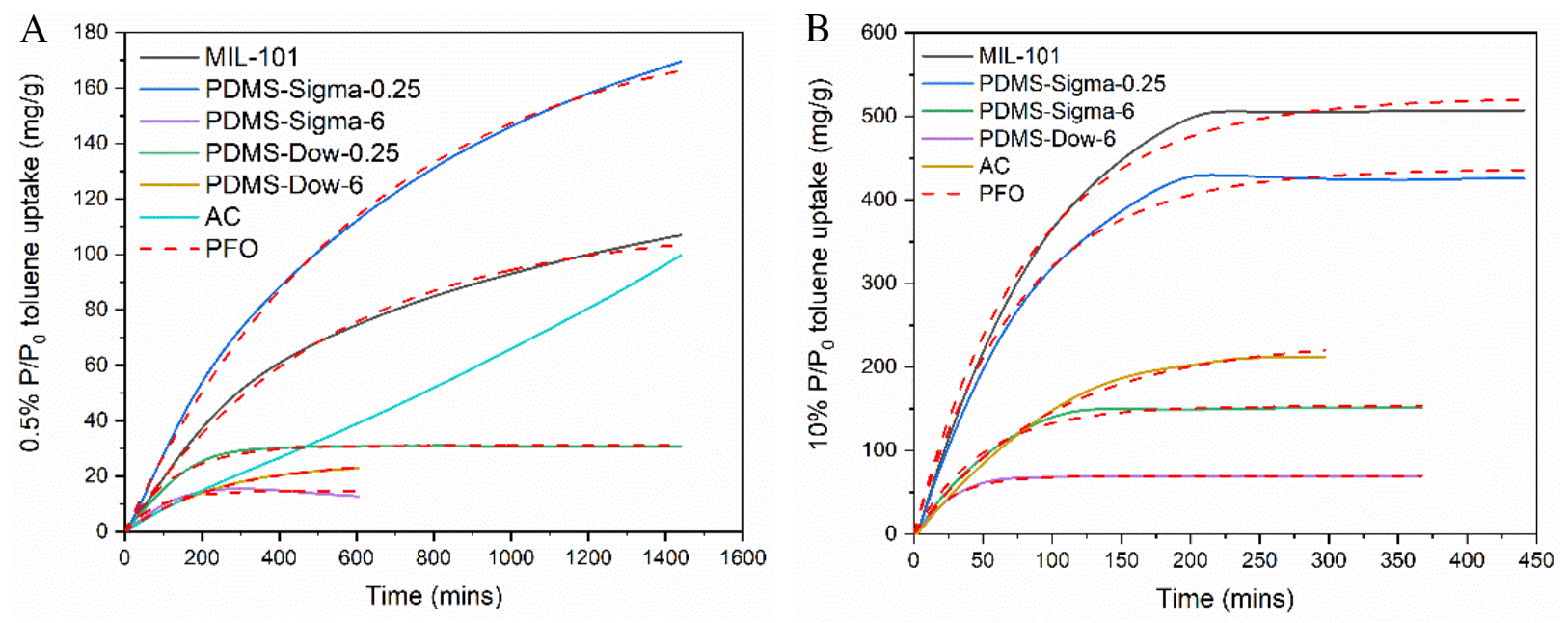

Figure 5. Adsorption kinetics at $40 \% \mathrm{RH}$ and at (A) $0.5 \%$ toluene $\mathrm{P} / \mathrm{P}_{0}$ and (B) at $10 \%$ toluene $\mathrm{P} / \mathrm{P}_{0}$. Solid lines are the experimental data whereas dashed lines are the fitted values obtained from pseudo first order (PFO) model. 
Kinetics modelling and analysis. Table 2 details the calculated pseudo first order (PFO) kinetics parameters for the results in Fehler! Verweisquelle konnte nicht gefunden werden.. The kinetics parameters could not be calculated for $\mathrm{AC}$ at $0.5 \% \mathrm{P} / \mathrm{P}_{0}$ toluene as the uptake did not reach equilibrium. The two main parameters derived from the model are maximum theoretical equilibrium capacity $\left(\mathrm{q}_{\mathrm{e}}\right)$ and PFO kinetics coefficient $\left(\mathrm{k}_{1}\right)$. Ideally, for practical and industrial applications, a material should have high values in both categories, meaning it will be able to adsorb a high quantity of adsorbate at a fast rate. For a better understanding of each material's performance and a convenient ranking assortment, a new metric is proposed by taking the product of the two $\left(\mathrm{q}_{\mathrm{e}} \cdot \mathrm{k}_{1}\right)$.

Table 2. Pseudo-first order kinetics model fitted parameters of all samples.

\begin{tabular}{|l|c|c|c|c|c|c|c|c|}
\hline \multirow{2}{*}{ Sample } & \multicolumn{7}{|c|}{ Pseudo-first order model parameter } \\
\cline { 2 - 10 } & \multicolumn{7}{|c|}{$0.5 \%$ P/P toluene } & \multicolumn{3}{c|}{$10 \% \mathrm{P} / \mathrm{P}_{0}$ toluene } \\
\cline { 2 - 9 } & $\begin{array}{c}\mathrm{q}_{\mathrm{e}} \\
(\mathrm{mg} / \mathrm{g})\end{array}$ & $\begin{array}{c}\mathrm{k}_{1} \times 10^{3} \\
\left(\mathrm{~min}^{-1}\right)\end{array}$ & $\begin{array}{c}\mathrm{q}_{\mathrm{e}} \cdot \mathrm{k}_{1} \\
(\mathrm{mg} / \mathrm{g} \cdot \mathrm{min})\end{array}$ & $\mathrm{R}^{2}$ & $\begin{array}{c}\mathrm{q}_{\mathrm{e}} \\
(\mathrm{mg} / \mathrm{g})\end{array}$ & $\begin{array}{c}\mathrm{k}_{1} \times 10^{3} \\
\left(\mathrm{~min}^{-1}\right)\end{array}$ & $\begin{array}{c}\mathrm{q}_{\mathrm{e}} \cdot \mathrm{k}_{1} \\
(\mathrm{mg} / \mathrm{g} \cdot \mathrm{min})\end{array}$ & $\mathrm{R}^{2}$ \\
\hline MIL-101 & 111 & 1.9 & 0.211 & 0.997 & 522 & 12.1 & 6.316 & 0.991 \\
\hline $\begin{array}{l}\text { MIL-PDMS- } \\
\text { Sigma-0.25 }\end{array}$ & 185 & 1.6 & 0.296 & 0.998 & 437 & 13.2 & 5.768 & 0.989 \\
\hline $\begin{array}{l}\text { MIL-PDMS- } \\
\text { Sigma-6 }\end{array}$ & 15 & 11.8 & 0.177 & 0.927 & 153 & 20 & 3.060 & 0.987 \\
\hline $\begin{array}{l}\text { MIL-PDMS- } \\
\text { Dow-0.25 }\end{array}$ & 31 & 7.8 & 0.242 & 0.989 & - & - & - & - \\
\hline $\begin{array}{l}\text { MIL-PDMS- } \\
\text { Dow-6 }\end{array}$ & 25 & 4.0 & 0.100 & 0.999 & 70 & 37.9 & 2.653 & 0.991 \\
\hline AC & - & - & - & - & 232 & 9.9 & 2.297 & 0.994 \\
\hline
\end{tabular}

At $0.5 \% \mathrm{P} / \mathrm{P}_{0}$ toluene, the increasing order of the best material is: AC, MIL-PDMS-Dow-6, MILPDMS-Sigma-6, MIL-101, MIL-PDMS-Dow-0.25, MIL-PDMS-Sigma-0.25. Although MIL- 
PDMS-Dow-0.25 showed a low $\mathrm{q}_{\mathrm{e}}$ and a high $\mathrm{k}_{1}$ which makes it suitable for applications where fast adsorption is required. This is possibly due to the water protection supplied by the PDMS coating which simultaneously improves toluene selectivity. Therefore, a PDMS coating which is optimized properly by minimizing pore blockage, can produce a very competitive adsorbent material.

At $10 \% \mathrm{P} / \mathrm{P}_{0}$ toluene, the pristine MIL-101 had the highest capacity, followed by MIL-PDMSSigma-0.25, MIL-PDMS-Sigma-6, MIL-PDMS-Dow-6 and lastly AC. Remarkably, MIL-PDMSSigma-0.25 has good performance at both toluene concentrations, suggesting this may be the right starting point for further optimization work. Compared to the MOFs, AC offers relatively modest performance which is only compensated for by its very low cost.

Moisture stability stress and reusability tests. Table S1 shows the moisture stability test results and the estimated PFO kinetics parameters for MIL-101, MIL-PDMS-Sigma-0.25 and AC. From this preliminary test, $\mathrm{AC}$ appears as a better option than the MOFs as its intrinsic hydrophobicity enabled consistent toluene uptake, unaffected by the transient extreme humidity environment. Figure S5 compares the amount of toluene adsorbed by the samples after being subjected to 10 adsorption cycles. The cyclic toluene test revealed the best of MIL-PDMS-Sigma0.25 as it demonstrated superior uptake capacity. Figure S6 is a focused plot of the materials' kinetics during the first adsorption cycle where the MOFs were observed to have faster kinetics than AC given their higher surface area and pore volume. 
Final remarks. A vapor deposition method using PDMS was employed to make MIL-101 hydrophobic. Long coatings times led to significant pore blockage, but an optimal time of $0.25 \mathrm{hr}$ using a low molecular weight PDMS polymer (PDMS-Sigma) was successful in coating MIL-101 such that no surface area or porosity was lost. MIL-PDMS-Sigma-0.25 was further assessed for competitive adsorption of toluene and water at $40 \% \mathrm{RH}$. Firstly, at $0.5 \% \mathrm{P} / \mathrm{P}_{0}$ toluene concentration which is relevant to VOC capture applications, MIL-PDMS-Sigma-0.25 demonstrated a 60\% higher toluene uptake $(170 \mathrm{mg} / \mathrm{g})$ than the regular MIL-101 $(107 \mathrm{mg} / \mathrm{g})$ with adsorption kinetics which are twice as fast. By increasing the toluene concentration up to $10 \% \mathrm{P} / \mathrm{P}_{0}$, MIL-101 achieved a higher uptake $(507 \mathrm{mg} / \mathrm{g})$ than MIL-PDMS-Sigma-0.25 (426 mg/g) which highlights the importance of original hydrophobic framework for higher toluene concentrations. On the other hand, the regeneration experiments favor the MIL-101-PDMS composite as it has higher surface area which resulted in superior capacity, kinetics, and stability. To conclude, an ideal VOC adsorbent should possess intrinsic hydrophobicity and high surface area to selectively adsorb a high quantity of VOC adsorbates at a fast rate from humid environments as demonstrated by this new MIL-101 PDMS composite.

\section{ACKNOWLEDGMENT}

The authors are grateful to Patricia Carry and Kaho Cheung for their assistance with adsorbent characterization experiments.

\section{FUNDING SOURCES}


L. H. Mohd Azmi would like to thank Yayasan Khazanah for the PhD sponsorship that made this work possible. E. Hunter-Sellars would like to thank the EPSRC Centre for Doctoral Training in Advanced Characterization of Materials (Grant Ref: EP/L015277/1), as well as Procter \& Gamble

Co., USA, for funding his work. P. Cherukupally and D. R. Williams are grateful for the Research England Global Challenges Research Fund.

\section{ASSOCIATED CONTENT}

\section{Supporting Information}

The data presented in the Figures in this manuscript is available from the open repository: https://doi.org/10.5281/zenodo.4633627

\section{AUTHOR INFORMATION}

\section{Corresponding Author}

*Corresponding author’s email: d.r.williams@imperial.ac.uk

\section{Author Contributions}

The manuscript was written through contributions of all authors. All authors have given approval to the final version of the manuscript.

\section{Notes}


The authors declare no competing financial interest. The graphical abstract was prepared using Biorender.

\section{REFERENCES}

(1) Shinohara, N.; Ángeles, F.; Basaldud, R.; Cardenas, B.; Wakamatsu, S. Reductions in Commuter Exposure to Volatile Organic Compounds in Mexico City Due to the Environmental Program ProAire2002-2010. J. Expo. Sci. Environ. Epidemiol. 2017, 27 (3), $339-345$.

(2) McDonald, B. C.; de Gouw, J. A.; Gilman, J. B.; Jathar, S. H.; Akherati, A.; Cappa, C. D.; Jimenez, J. L.; Lee-Taylor, J.; Hayes, P. L.; McKeen, S. A. Volatile Chemical Products Emerging as Largest Petrochemical Source of Urban Organic Emissions. Science. 2018, 359 (6377), 760-764.

(3) Salthammer, T.; Schieweck, A.; Gu, J.; Ameri, S.; Uhde, E. Future Trends in Ambient Air Pollution and Climate in Germany-Implications for the Indoor Environment. Build. Environ. 2018, 143, 661-670.

(4) Cancelada, L.; Sleiman, M.; Tang, X.; Russell, M. L.; Montesinos, V. N.; Litter, M. I.; Gundel, L. A.; Destaillats, H. Heated Tobacco Products: Volatile Emissions and Their Predicted Impact on Indoor Air Quality. Environ. Sci. Technol. 2019, 53 (13), 7866-7876.

(5) Katsoyiannis, A.; Cincinelli, A. 'Cocktails and Dreams': The Indoor Air Quality That People Are Exposed to While Sleeping. Curr. Opin. Environ. Sci. Heal. 2019, 8, 6-9.

(6) Goldstein, A. H.; Nazaroff, W. W.; Weschler, C. J.; Williams, J. How Do Indoor 
Environments Affect Air Pollution Exposure? Environ. Sci.Technol.2020.

(7) Sheu, R.; Stönner, C.; Ditto, J. C.; Klüpfel, T.; Williams, J.; Gentner, D. R. Human Transport of Thirdhand Tobacco Smoke: A Prominent Source of Hazardous Air Pollutants into Indoor Nonsmoking Environments. Sci. $A d v . \mathbf{2 0 2 0}, 6(10), 1-14$.

(8) Cavaleiro Rufo, J.; Madureira, J.; Oliveira Fernandes, E.; Moreira, A. Volatile Organic Compounds in Asthma Diagnosis: A Systematic Review and Meta-analysis. Allergy 2016, $71(2), 175-188$.

(9) Tham, K. W. Indoor Air Quality and Its Effects on Humans-A Review of Challenges and Developments in the Last 30 Years. Energy Build. 2016, 130, 637-650.

(10) Steinemann, A. Ten Questions Concerning Air Fresheners and Indoor Built Environments. Build. Environ. 2017, 111, 279-284.

(11) Çankaya, S.; Pekey, H.; Pekey, B.; Özerkan Aydın, B. Volatile Organic Compound Concentrations and Their Health Risks in Various Workplace Microenvironments. Hum. Ecol. Risk Assess. An Int. J. 2020, 26 (3), 822-842.

(12) Song, S.-K.; Shon, Z.-H.; Kang, Y.-H.; Kim, K.-H.; Han, S.-B.; Kang, M.; Bang, J.-H.; Oh, I. Source Apportionment of VOCs and Their Impact on Air Quality and Health in the Megacity of Seoul. Environ. Pollut. 2019, 247, 763-774.

(13) Lu, X.; Zhang, L.; Wang, X.; Gao, M.; Li, K.; Zhang, Y.; Yue, X.; Zhang, Y. Rapid Increases in Warm-Season Surface Ozone and Resulting Health Impact in China since 2013. Environ. Sci. Technol. Lett. 2020, 7 (4), 240-247. 
(14) Mishra, N.; Bartsch, J.; Ayoko, G. A.; Salthammer, T.; Morawska, L. Volatile Organic Compounds: Characteristics, Distribution and Sources in Urban Schools. Atmos. Environ. 2015, 106, 485-491.

(15) Salthammer, T.; Zhang, Y.; Mo, J.; Koch, H. M.; Weschler, C. J. Assessing Human Exposure to Organic Pollutants in the Indoor Environment. Angew. Chemie Int. Ed. 2018, $57(38), 12228-12263$.

(16) Duan, H.; Liu, X.; Yan, M.; Wu, Y.; Liu, Z. Characteristics of Carbonyls and Volatile Organic Compounds (VOCs) in Residences in Beijing, China. Front. Environ. Sci. Eng. 2016, 10 (1), 73-84.

(17) Goodman, N. B.; Wheeler, A. J.; Paevere, P. J.; Selleck, P. W.; Cheng, M.; Steinemann, A. Indoor Volatile Organic Compounds at an Australian University. Build. Environ. 2018, 135, 344-351.

(18) Rosenberger, W. Effect of Charcoal Equipped HEPA Filters on Cabin Air Quality in Aircraft. A Case Study Including Smell Event Related in-Flight Measurements. Build. Environ. 2018, 143, 358-365.

(19) Heo, K. J.; Noh, J. W.; Lee, B. U.; Kim, Y.; Jung, J. H. Comparison of Filtration Performance of Commercially Available Automotive Cabin Air Filters against Various Airborne Pollutants. Build. Environ. 2019, 161, 106272.

(20) Xie, L.-H.; Liu, X.-M.; He, T.; Li, J.-R. Metal-Organic Frameworks for the Capture of Trace Aromatic Volatile Organic Compounds. Chem 2018, 4 (8), 1911-1927. 
(21) McGuire, C. V; Forgan, R. S. The Surface Chemistry of Metal-Organic Frameworks. Chem. Commun. 2015, 51 (25), 5199-5217.

(22) Wang, T.; Gu, J.; Cui, Q.; Wang, H. Study on Adsorption and Desorption Performances of Trace C4-C6 Alkane Mixture on MIL-101 (Cr) and WS-480. Energy \& Fuels 2019, 33 (8), 7587-7594.

(23) Hunter-Sellars, E.; Tee, J. J.; Parkin, I. P.; Williams, D. R. Adsorption of Volatile Organic Compounds by Industrial Porous Materials: Impact of Relative Humidity. Microporous Mesoporous Mater. 2020, 298, 110090.

(24) Xie, L. H.; Xu, M. M.; Liu, X. M.; Zhao, M. J.; Li, J. R. Hydrophobic Metal-Organic Frameworks: Assessment, Construction, and Diverse Applications. Adv. Sci. 2020, 7 (4). https://doi.org/10.1002/advs.201901758.

(25) Li, X.; Zhang, L.; Yang, Z.; Wang, P.; Yan, Y.; Ran, J. Adsorption Materials for Volatile Organic Compounds (VOCs) and the Key Factors for VOCs Adsorption Process: A Review. Sep. Purif. Technol. 2020, 235, 116213.

(26) Férey, G.; Draznieks-Mellot, C.; Serre, C.; Millange, F.; Dutour, F.; Surblé, S.; Margiolaki, I. A Chromium Terephthalate-Based Solid with Unusually Large Pore Volumes and Surface Area. Science. 2005, 309 (5743), 2040-2042. https://doi.org/10.1126/science.1116275.

(27) Lebedev, O. I.; Millange, F.; Serre, C.; Van Tendeloo, G.; Férey, G. First Direct Imaging of Giant Pores of the Metal-Organic Framework MIL-101. Chem. Mater. 2005, 17 (26), 6525-6527. https://doi.org/10.1021/cm051870o. 
(28) Huang, C. Y.; Song, M.; Gu, Z. Y.; Wang, H. F.; Yan, X. P. Probing the Adsorption Characteristic of Metal-Organic Framework MIL-101 for Volatile Organic Compounds by Quartz Crystal Microbalance. Environ. Sci. Technol. 2011, 45 (10), 4490-4496. https://doi.org/10.1021/es200256q.

(29) Zhao, Z.; Li, X.; Li, Z. Adsorption Equilibrium and Kinetics of P-Xylene on ChromiumBased Metal Organic Framework MIL-101. Chem. Eng. J. 2011, 173 (1), 150-157.

(30) Xian, S.; Yu, Y.; Xiao, J.; Zhang, Z.; Xia, Q.; Wang, H.; Li, Z. Competitive Adsorption of Water Vapor with VOCs Dichloroethane, Ethyl Acetate and Benzene on MIL-101 (Cr) in Humid Atmosphere. RSC Adv. 2015, 5 (3), 1827-1834.

(31) Wang, X.; Ma, C.; Xiao, J.; Xia, Q.; Wu, J.; Li, Z. Benzene/Toluene/Water Vapor Adsorption and Selectivity of Novel C-PDA Adsorbents with High Uptakes of Benzene and Toluene. Chem. Eng. J. 2018, 335, 970-978.

(32) Ehrenmann, J.; Henninger, S. K.; Janiak, C. Water Adsorption Characteristics of MIL-101 for Heat-Transformation Applications of MOFs. Eur. J. Inorg. Chem. 2011, No. 4, 471474. https://doi.org/10.1002/ejic.201001156.

(33) Seo, Y. K.; Yoon, J. W.; Lee, J. S.; Hwang, Y. K.; Jun, C. H.; Chang, J. S.; Wuttke, S.; Bazin, P.; Vimont, A.; Daturi, M.; Bourrelly, S.; Llewellyn, P. L.; Horcajada, P.; Serre, C.; Férey, G. Energy-Efficient Dehumidification over Hierachically Porous Metal-Organic Frameworks as Advanced Water Adsorbents. Adv. Mater. 2012, 24 (6), 806-810. https://doi.org/10.1002/adma.201104084.

(34) Canivet, J.; Fateeva, A.; Guo, Y.; Coasne, B.; Farrusseng, D. Water Adsorption in MOFs: 
Fundamentals and Applications. Chem. Soc. Rev. 2014, 43 (16), 5594-5617. https://doi.org/10.1039/C4CS00078A.

(35) Bhattacharjee, S.; Chen, C.; Ahn, W.-S. Chromium Terephthalate Metal-Organic Framework MIL-101: Synthesis, Functionalization, and Applications for Adsorption and Catalysis. RSC Adv. 2014, 4 (94), 52500-52525.

(36) Akiyama, G.; Matsuda, R.; Sato, H.; Hori, A.; Takata, M.; Kitagawa, S. Effect of Functional Groups in MIL-101 on Water Sorption Behavior. Microporous Mesoporous Mater. 2012, 157, 89-93. https://doi.org/10.1016/j.micromeso.2012.01.015.

(37) Ko, N.; Choi, P. G.; Hong, J.; Yeo, M.; Sung, S.; Cordova, K. E.; Park, H. J.; Yang, J. K.; Kim, J. Tailoring the Water Adsorption Properties of MIL-101 Metal-Organic Frameworks by Partial Functionalization. J. Mater. Chem. A 2015, 3 (5), 2057-2064.

(38) Yanagita, K.; Hwang, J.; Shamim, J. A.; Hsu, W. L.; Matsuda, R.; Endo, A.; Delaunay, J. J.; Daiguji, H. Kinetics of Water Vapor Adsorption and Desorption in MIL-101 MetalOrganic Frameworks. J. Phys. Chem. $\quad$ C 2019,123 (1), 387-398. https://doi.org/10.1021/acs.jpcc.8b08211.

(39) Yang, C.; Kaipa, U.; Mather, Q. Z.; Wang, X.; Nesterov, V.; Venero, A. F.; Omary, M. A. Fluorous Metal-Organic Frameworks with Superior Adsorption and Hydrophobic Properties toward Oil Spill Cleanup and Hydrocarbon Storage. J. Am. Chem. Soc. 2011, 133 (45), 18094-18097. https://doi.org/10.1021/ja208408n.

(40) Zhu, M.; Hu, P.; Tong, Z.; Zhao, Z.; Zhao, Z. Enhanced Hydrophobic MIL(Cr) MetalOrganic Framework with High Capacity and Selectivity for Benzene VOCs Capture from 
High Humid Air. Chem. Eng. J. 2017, 313, 1122-1131. https://doi.org/10.1016/j.cej.2016.11.008.

(41) Karikkethu Prabhakaran, P.; Deschamps, J. Doping Activated Carbon Incorporated Composite MIL-101 Using Lithium: Impact on Hydrogen Uptake. J. Mater. Chem. A 2015, 3 (13), 7014-7021. https://doi.org/10.1039/c4ta07197b.

(42)

Zhang, F.; Sang, X.; Tan, X.; Liu, C.; Zhang, J.; Luo, T.; Liu, L.; Han, B.; Yang, G.; Binks, B. P. Converting Metal-Organic Framework Particles from Hydrophilic to Hydrophobic by an Interfacial Assembling Route. Langmuir 2017, 33 (43), 12427-12433. https://doi.org/10.1021/acs.langmuir.7b02365.

(43) Sun, Q.; He, H.; Gao, W.-Y.; Aguila, B.; Wojtas, L.; Dai, Z.; Li, J.; Chen, Y.-S.; Xiao, F.S.; Ma, S. Imparting Amphiphobicity on Single-Crystalline Porous Materials. Nat. Commun. 2016, 7, 13300.

(44) Thurgood, P.; Baratchi, S.; Szydzik, C.; Mitchell, A.; Khoshmanesh, K. Porous PDMS Structures for the Storage and Release of Aqueous Solutions into Fluidic Environments. Lab Chip 2017, 17 (14), 2517-2527.

(45) Berean, K.; Ou, J.Z.; Nour, M.; Latham, K.; McSweeney, C.; Paull, D.; Halim, A.; Kentish, S.; Doherty, C. M.; Hill, A. J. The Effect of Crosslinking Temperature on the Permeability of PDMS Membranes: Evidence of Extraordinary $\mathrm{CO}_{2}$ and $\mathrm{CH}_{4}$ Gas Permeation. Sep. Purif. Technol. 2014, 122, 96-104.

(46) Fang, M.; Zhang, G.; Liu, Y.; Xiong, R.; Wu, W.; Yang, F.; Liu, L.; Chen, J.; Li, J. Exploiting Giant-Pore Systems of Nanosized MIL-101 in PDMS Matrix for Facilitated 
Reverse-Selective Hydrocarbon Transport. ACS Appl. Mater. Interfaces 2019, 12 (1), 15111522.

(47) Yuan, J.; Liu, X.; Akbulut, O.; Hu, J.; Suib, S. L.; Kong, J.; Stellacci, F. Superwetting Nanowire Membranes for Selective Absorption. Nat. Nanotechnol. 2008, 3 (6), 332-336. https://doi.org/10.1038/nnano.2008.136.

(48) Zhang, W.; Hu, Y.; Ge, J.; Jiang, H. L.; Yu, S. H. A Facile and General Coating Approach to Moisture/Water-Resistant Metal-Organic Frameworks with Intact Porosity. J. Am. Chem. Soc. 2014, 136 (49), 16978-16981. https://doi.org/10.1021/ja509960n.

(49) Huang, G.; Yang, Q.; Xu, Q.; Yu, S.; Jiang, H. Polydimethylsiloxane Coating for a Palladium/MOF Composite: Highly Improved Catalytic Performance by Surface Hydrophobization. Angew. Chemie Int. Ed. 2016, 55 (26), 7379-7383.

(50) Xu, X.-Y.; Yan, B. Nanoscale LnMOF-Functionalized Nonwoven Fibers Protected by a Polydimethylsiloxane Coating Layer as a Highly Sensitive Ratiometric Oxygen Sensor. $J$. Mater. Chem. C 2016, 4 (36), 8514-8521.

(51) Kang, M.; Kim, J. E.; Kang, D. W.; Lee, H. Y.; Moon, D.; Hong, C. S. A Diamine-Grafted Metal-Organic Framework with Outstanding CO2 Capture Properties and a Facile Coating Approach for Imparting Exceptional Moisture Stability. J. Mater. Chem. A 2019, 7 (14), 8177-8183. https://doi.org/10.1039/c8ta07965j.

(52) He, S.; Chen, L.; Cui, J.; Yuan, B.; Wang, H.; Wang, F.; Yu, Y.; Lee, Y.; Li, T. General Way to Construct Micro- And Mesoporous Metal-Organic Framework-Based Porous Liquids. J. Am. Chem. Soc. 2020, $141 \quad$ (50), 19708-19714. 
https://doi.org/10.1021/jacs.9b08458.

(53) Azmi, L. H. M.; Williams, D.; Ladewig, B. P. Can Metal Organic Frameworks Outperform Adsorptive Removal of Harmful Phenolic Compound 2-Chlorophenol by Activated Carbon? Chem. Eng. Res. Des. 2020, 158, 102-113.

(54) Clearco. Properties of Polydimethylsiloxane Fluids; 2015.

(55) Hunter-Sellars, E.; Saenz-Cavazos, P. A.; Houghton, A. R.; McIntyre, S. R.; Parkin, I. P.; Williams, D. R. Sol-Gel Synthesis of High-Density Zeolitic Imidazolate Framework Monoliths via Ligand Assisted Methods: Exceptional Porosity, Hydrophobicity, and Applications in Vapor Adsorption. Adv. Funct. Mater. 2021, 31 (5), 2008357.

(56) Halasz, I.; Agarwal, M.; Marcus, B.; Cormier, W. E. Molecular Spectra and Polarity Sieving of Aluminum Deficient Hydrophobic HY Zeolites. Microporous Mesoporous Mater. 2005, $84(1-3), 318-331$.

(57) Bhadra, B. N.; Cho, K. H.; Khan, N. A.; Hong, D. Y.; Jhung, S. H. Liquid-Phase Adsorption of Aromatics over a Metal-Organic Framework and Activated Carbon: Effects of Hydrophobicity/Hydrophilicity of Adsorbents and Solvent Polarity. J. Phys. Chem.C 2015, 119 (47), 26620-26627. https://doi.org/10.1021/acs.jpcc.5b09298.

(58) Cho, K. H.; Chitale, S. K.; Kim, S.-J.; Cha, G.-Y.; Hong, D.-Y.; Ryu, S. G.; Chang, J.-S.; Hwang, Y. K. Adsorptive Removal of Nerve-Agent Simulant with Zirconium-Based MetalOrganic Frameworks Modified by Hydrophobic Monocarboxylic Acids. Microporous Mesoporous Mater. 2019, 285, 61-69. 
(59) Giaya, A.; Thompson, R. W.; Denkewicz Jr, R. Liquid and Vapor Phase Adsorption of Chlorinated Volatile Organic Compounds on Hydrophobic Molecular Sieves. Microporous Mesoporous Mater. 2000, 40 (1-3), 205-218.

(60) Van Durme, J.; Dewulf, J.; Sysmans, W.; Leys, C.; Van Langenhove, H. Abatement and Degradation Pathways of Toluene in Indoor Air by Positive Corona Discharge. Chemosphere 2007, 68 (10), 1821-1829.

(61) Qin, C.; Wen, G.; Wang, X.; Song, L.; Huang, X. Ultra-Long Sialon Nanobelts: Large-Scale Synthesis via a Pressure Enhanced CVD Process and Photoluminescence Characteristics. J. Mater. Chem. 2011, 21 (16), 5985-5991.

(62) Jayaramulu, K.; Geyer, F.; Schneemann, A.; Kment, Š.; Otyepka, M.; Zboril, R.; Vollmer, D.; Fischer, R. A. Hydrophobic Metal-Organic Frameworks. Adv. Mater. 2019, 31 (32), 131. https://doi.org/10.1002/adma.201900820.

(63) Gao, Z.; Song, G.; Zhang, X.; Li, Q.; Yang, S.; Wang, T.; Li, Y.; Zhang, L.; Guo, L.; Fu, Y. A Facile PDMS Coating Approach to Room-Temperature Gas Sensors with High Humidity Resistance and Long-Term Stability. Sensors Actuators B Chem. 2020, 325, 128810.

(64) Küsgens, P.; Rose, M.; Senkovska, I.; Fröde, H.; Henschel, A.; Siegle, S.; Kaskel, S. Characterization of Metal-Organic Frameworks by Water Adsorption. Microporous Mesoporous $\quad$ Mater $\quad$ 2009, $\quad 120 \quad 325-330$. https://doi.org/10.1016/j.micromeso.2008.11.020.

(65) Cui, S.; Qin, M.; Marandi, A.; Steggles, V.; Wang, S.; Feng, X.; Nouar, F.; Serre, C. Metal- 
Organic Frameworks as Advanced Moisture Sorbents for Energy-Efficient High Temperature Cooling. Sci. Rep. 2018, 8 (1), 15284.

(66) Kim, K.-H.; Szulejko, J. E.; Raza, N.; Kumar, V.; Vikrant, K.; Tsang, D. C. W.; Bolan, N. S.; Ok, Y. S.; Khan, A. Identifying the Best Materials for the Removal of Airborne Toluene Based on Performance Metrics-A Critical Review. J. Clean. Prod. 2019, 241, 118408.

(67) Yang, K.; Sun, Q.; Xue, F.; Lin, D. Adsorption of Volatile Organic Compounds by MetalOrganic Frameworks MIL-101: Influence of Molecular Size and Shape. J. Hazard. Mater. 2011, 195, 124-131.

(68) Li, Y.-Z.; Wang, G.-D.; Shi, W.-J.; Hou, L.; Wang, Y.-Y.; Zhu, Z. Efficient C ${ }_{2} H n$ Hydrocarbons and VOC Adsorption and Separation in an MOF with Lewis Basic and Acidic Decorated Active Sites. ACS Appl. Mater. Interfaces 2020, 12 (37), 41785-41793. 